\title{
APPENDICITIS IN CHILDREN: SYMPTOMS AND SIGNS, LABORATORY AND HISTOPATHOLOGY FINDINGS IN 67 PATIENTS
}

\author{
Dragoljub Živanovic ${ }^{1,2}$, Ivona Đorđevic ${ }^{1,2}$, Milan Petrovic ${ }^{1 *}$ \\ ${ }^{1}$ University of Niš Faculty of Medicine, Niš, Serbia \\ ${ }^{2}$ Clinical Center Niš, Clinic for Pediatric Surgery and Orthopedics, Niš, Serbia
}

\begin{abstract}
Acute abdominal pain is a reason for hospital admission of about $20 \%$ of children. Typical clinical presentation of appendicitis may be significantly different in children. Diagnosis is based on the combination of symptoms, clinical signs, and results of laboratory and radiology examinations. The objective of the present study was to analyze symptoms, signs, laboratory and histopathology findings in children who underwent surgery for acute appendicitis. Sixty-seven patients (37 males and 30 females) with mean age of 9.77 years, operated on for clinical diagnosis of acute appendicitis were enrolled in the study. Abdominal pain was present in all patients, followed by vomitus and fever. Laboratory markers of inflammation varied significantly with severity of inflammation, but were normal in chronic appendicitis. Clinical and histopathology assessments of inflammation were concordant in $22-43 \%$ depending of the degree of appendicitis. Perforation occurred in $26.86 \%$ and negative appendectomy rate was $6 \%$.
\end{abstract}

Key words: appendicitis, children, appendectomy, histopathology.

\section{Introduction}

Acute abdominal pain constitutes $20 \%$ of all pediatric surgery admissions [1]. Typical clinical presentation of appendicitis that includes pain, nausea, vomiting and low-grade fever sometimes accompanied by constipation or diarrhea may significantly differ in children[2]. A child may present with very few symptoms and in good general health or in very severe general condition with signs of septic shock and/or bowel obstruction. Decision making is based on the clinical course, physical signs, laboratory and radiology findings. Overall rupture rates varied from $20 \%$ to $76 \%$, with a median of $36 \%$ in a recent analysis of data from 30 pediatric hospitals in the United States [3]. Perforation rate is reported to be higher in children younger than 5 , and is nearly $100 \%$ in those younger than 3 years [4,5]. Delay in diagnosis is associated with increased risk of perforation, and it correlates more with pre-hospital than with in-hospital delay $[6,7]$.

Despite the improvement in diagnosis, some of the appendices removed under high clinical suspicion of acute appendicitis turn out to be normal on histopathology (negative appendectomies - NA). Recent researches revealed that some of them had manifested the signs of

Correspondence to: Dragoljub Živanović, M.D., PhD

Faculty of Medicine, University of Niš

81 Dr. Zorana Đindića, 18000 Niš, Serbia

Phone: +381646389999

E-mail: dzivanovic.nis@gmail.com

Received May $9^{\text {th }}, 2017$, accepted for publication September $26^{\text {th }}, 2017$

PhD Student inflammation on more detailed examination or on immunohistochemistry [8-10].

White blood cell (WBC) count, percentage of neutrophils $(\mathrm{Ne} \%)$ and $\mathrm{C}$-reactive protein level (CRP) are the most commonly used laboratory markers [11,12], with combined specificity of $95 \%$ for acute and $100 \%$ for perforated appendicitis [13]. Recently, neutrophil/lymphocyte ratio (NLR) was reported as more reliable marker of acute appendicitis than WBC count [14], and values of NLR higher than 3.5 were strongly associated with acute appendicitis.

Objective of the present study was to analyze symptoms and signs, laboratory and histopathology findings in children who underwent surgery for acute appendicitis.

\section{Materials and Methods}

Sixty-seven patients, operated on for clinical diagnosis of acute appendicitis, were enrolled in the study.

Data on patients' demographics, history, symptoms and signs at presentation, physical and laboratory findings were obtained from the medical records. Clinical classification of the degree of inflammation made by treating surgeon has been obtained from operative reports. All removed appendices were routinely sent to histopathology examination. The histopathology classification was based on pathologists' reports. Pathologists were blinded for clinical classification of the degree of inflammation.

Collected data were entered in prepared MS Excel 2007 (C) spread sheet. Statistical analysis was performed using Graph Pad Prism 5@ statistical software. 


\section{Results}

Mean age of patients was $9.77 \pm 2.88$ years (range 4.25 - 15.75). There were 37 males and 30 females. Patients' demographics are summarized in Table 1. Forty-one $(61 \%)$ patients came from urban, and $26(39 \%)$ from the rural areas. Forty-nine (73\%) patients were from local community while 18 patients $(27 \%)$ had been referred from the surrounding secondary level regional general hospitals (RGH). Ten out of 18 referred patients $(55 \%)$ presented with perforation.

All patients complained of abdominal pain. Symptoms and their duration are summarized in Table 2. Fortythree patients vomited before admission. Thirty-four patients had normal body temperature. After admission, only 10 patients remained afebrile. Seventeen patients presented with constipation and 11 with diarrhea. Table 3 summarizes the presence of the signs of appendicitis.
Mean value of WBC count was $16.24 \times 10^{3} / \mu \mathrm{L}$ Mean percentage of neutrophils was $73.79 \%$ and average NLR ratio was 6.08. Mean value of CRP was 54.38 $\mathrm{mg} / \mathrm{ml}$ (Table 4).

Time from admission to operation varied with severity of inflammation (Figure 1). Clinical and histopathology diagnoses, as well as concordance of clinical and histopathology assessment of the degree of inflammation are given in Table 5 and Figure 2. Pediatric surgeon's and pathologist's reports were concordant in $35 \%$ of acute, $43 \%$ of phlegmonous, $33 \%$ of gangrenous and $22 \%$ of perforated appendices. Overall concordance in clinical and histopathology reports was $33.34 \%$ (21 of 67 patients). According to Cohen's kappa coefficient $(\mathrm{Kappa}=0.141)$, the strength of agreement was considered to be poor.

Table 1 Demographic data of patients operated on with diagnosis of acute appendicitis

\begin{tabular}{lrrrrrrr}
\hline $\begin{array}{l}\text { Histopathology } \\
\text { grade of }\end{array}$ & $\begin{array}{c}\text { Age } \\
\text { inflammation }\end{array}$ & & \multicolumn{2}{c}{ Gender } & \multicolumn{2}{c}{ Living area } & \multicolumn{2}{c}{ Referral } \\
\cline { 3 - 8 } \pm (mean) & Male & Female & Urban & Rural & Local & RGH \\
\hline Acute & $8.88 \pm 2.81$ & 4 & 6 & 2 & 4 & 6 & 4 \\
Phlegmonous & $9.38 \pm 3.09$ & 16 & 15 & 19 & 12 & 23 & 8 \\
Gangrenous & $10.78 \pm 2.52$ & 9 & 4 & 8 & 5 & 9 & 4 \\
Perforated & $10.80 \pm 2.23$ & 4 & 1 & 1 & 4 & 3 & 2 \\
Chronic & $11.54 \pm 1.65$ & 1 & 3 & 3 & 1 & 4 & 0 \\
Normal (NA) & $8.73 \pm 3.56$ & 3 & 1 & 4 & 0 & 4 & 0 \\
\hline Total & $9.77 \pm 2.88$ & 37 & 30 & 41 & 26 & 49 & 18 \\
\hline
\end{tabular}

Table 2 Symptoms of appendicitis and its duration

\begin{tabular}{|c|c|c|c|c|c|c|c|c|}
\hline \multicolumn{9}{|c|}{ Symptoms } \\
\hline \multirow{3}{*}{ Duration } & \multirow{2}{*}{\multicolumn{2}{|c|}{ Vomitus }} & \multicolumn{6}{|c|}{ Body temperature } \\
\hline & & & \multicolumn{3}{|c|}{ Before admission } & \multicolumn{3}{|c|}{ After admission } \\
\hline & Yes & No & $<36.9$ & $37.0-37.9$ & $>38.0$ & $<36.9$ & $37.0-37.9$ & $>38.0$ \\
\hline$<6 h$ & 3 & 5 & 6 & 1 & 1 & 1 & 6 & 1 \\
\hline $6-12 h$ & 7 & 1 & 4 & 1 & 3 & 1 & 4 & 3 \\
\hline $12-24 h$ & 23 & 7 & 17 & 9 & 4 & 4 & 17 & 9 \\
\hline $24-48 h$ & 6 & 5 & 2 & 2 & 7 & 1 & 3 & 7 \\
\hline$>48 \mathrm{~h}$ & 4 & 6 & 5 & 3 & 2 & 3 & 3 & 4 \\
\hline Total & 43 & 24 & 34 & 16 & 17 & 10 & 33 & 24 \\
\hline
\end{tabular}

Table 3 Presence of signs of appendicitis

\begin{tabular}{lcccc}
\hline Sign & no & yes & n/a & $(\%)$ \\
\hline Abdominal tenderness & 0 & 67 & 0 & 100.0 \\
Rebound tenderness (Blumberg's sign) & 16 & 28 & 23 & 41.8 \\
Localized guarding & 59 & 8 & 0 & 11.9 \\
Diffuse guarding (defense) & 58 & 9 & 0 & 13.4 \\
Diarrhea & 53 & 11 & 3 & 16.4 \\
Constipation & 47 & 17 & 3 & 25.4 \\
\hline
\end{tabular}

$\mathrm{n} / \mathrm{a}$ - not applicable (presence or absence of sign was not recorded) 
Table 4 Mean values of laboratory markers of inflammation (WBC, \% of neutrophils, Ne/Ly ratio and CRP) in study groups and in different grades of appendicitis

\begin{tabular}{|c|c|c|c|c|c|}
\hline \multirow{2}{*}{$\begin{array}{l}\text { Histopathology } \\
\text { of inflammation }\end{array}$} & \multirow{2}{*}{ grade } & \multicolumn{4}{|c|}{ Laboratory marker of inflammation $($ mean \pm SD) } \\
\hline & & $\begin{array}{l}\text { WBC count } \\
\left(\mathrm{n} \times 10^{3} / \mu \mathrm{L}\right)\end{array}$ & $\mathrm{Ne} \%{ }^{\dagger}$ & NLR & $\begin{array}{c}\mathrm{CRP}^{\S} \\
(\mathrm{mg} / \mathrm{ml})\end{array}$ \\
\hline Acute & & $13.55 \pm 6.23$ & $67.53 \pm 11.92^{*}$ & $7.1 \pm 10.92$ & $35.40 \pm 44.07$ \\
\hline Phlegmonous & & $17.36 \pm 6.39$ & $78.08 \pm 9.74 \%$, & $6.0 \pm 3.20^{\epsilon}$ & $49.85 \pm 71.68$ \\
\hline Gangrenous & & $16.45 \pm 4.03$ & $76.41 \pm 18.65$ & $6.8 \pm 3.17^{\mathfrak{f}}$ & $66.41 \pm 67.28$ \\
\hline Perforated & & $22.34 \pm 7.88$ & $81.60 \pm 11.58^{¥}$ & $16.2 \pm 10.87$ & $66.41 \pm 67.28$ \\
\hline Chronic & & $8.175 \pm 1.87 *$ & $61.45 \pm 9.85^{\$, ¥}$ & $2.2 \pm 1.31^{€, £}$ & $13.41 \pm 11.98$ \\
\hline Normal (NA) & & $14.00 \pm 9.34$ & $68.15 \pm 14.91$ & $3.9 \pm 2.74$ & $55.86 \pm 67.26$ \\
\hline Total & & $16.24 \pm 6.59$ & $73.79 \pm 10.41$ & $6.1 \pm 4.98$ & $54.38 \pm 67.45$ \\
\hline
\end{tabular}

WBC - White blood cells; $\mathrm{Ne} \%$ - percent of neutrophils; NLR - Neutrophil to lymphocyte ratio; CRP - C-reactive protein; NA - negative appendectomy. *Mean WBC count was significantly lower in chronic appendicitis $(\mathrm{p}<0.05)$. $\dagger$ Differences in $\mathrm{Ne} \%$ among histology groups were significant ( $\mathrm{p}<0.05$; One-way ANOVA) $\$ \mathrm{p}<0.05, \$<0.01 ; ¥ \mathrm{p}<0.05$. Significant differences in NLR were observed between phlegmonose and chronic $€ p<0.05$ and gangrenous and chronic appendicitis $£ p<0.05$. § Differences in mean values of CRP were not significant $(p>0.05)$.

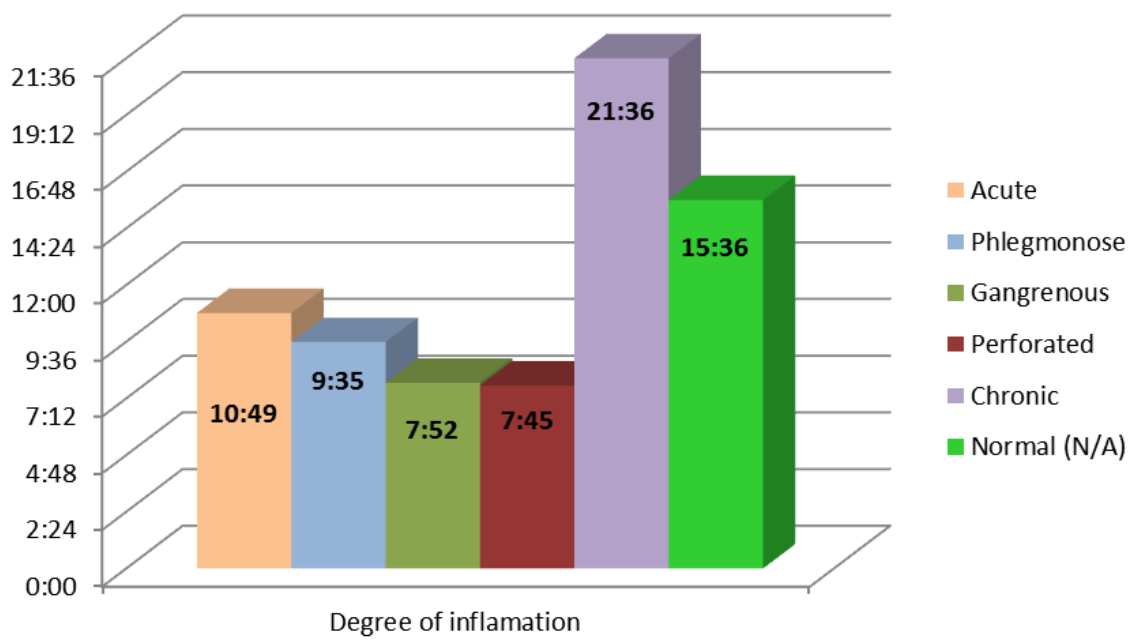

Fig. 1 Time from admission to surgery in relation to intensity of inflammation

Table 5 Distribution of clinical and histopathology degree of inflammation and concordance between clinical and histopathology findings.

\begin{tabular}{|c|c|c|c|c|c|c|c|c|c|c|}
\hline \multicolumn{3}{|c|}{$\begin{array}{c}\text { Clinical } \\
\text { diagnosis }\end{array}$} & \multicolumn{6}{|c|}{$\begin{array}{c}\text { Histopathology } \\
\text { diagnosis }\end{array}$} & \multicolumn{2}{|c|}{$\begin{array}{c}\text { Concordant } \\
\text { diagnoses }\end{array}$} \\
\hline $\begin{array}{l}\text { Degree of } \\
\text { inflammation }\end{array}$ & No & $\%$ & Acute & Phlegmonous & Gangrenous & Perforated & Chronic & $\begin{array}{c}\text { Normal } \\
\text { (N/A) }\end{array}$ & No & $\%$ \\
\hline Acute & 20 & 29.85 & 6 & 9 & 0 & 0 & 1 & 4 & 6 & 30.00 \\
\hline Phlegmonous & 14 & 20.90 & 4 & 6 & 1 & 0 & 3 & 0 & 6 & 42.86 \\
\hline Gangrenous & 15 & 22.39 & 0 & 9 & 5 & 1 & 0 & 0 & 5 & 33.33 \\
\hline Perforated & 18 & 26.87 & 0 & 7 & 7 & 4 & 0 & 0 & 4 & 22.22 \\
\hline Chronic & 0 & 0.00 & 0 & 0 & 0 & 0 & 0 & 0 & 0 & 0.00 \\
\hline Normal (N/A) & 0 & 0.00 & 0 & 0 & 0 & 0 & 0 & 0 & 0 & 0.00 \\
\hline Total & 67 & 100 & 10 & 31 & 13 & 5 & 4 & 4 & 21 & \\
\hline$\%$ & & & 14.93 & 46.27 & 19.40 & 7.46 & 5.97 & 5.97 & 31.34 & \\
\hline
\end{tabular}



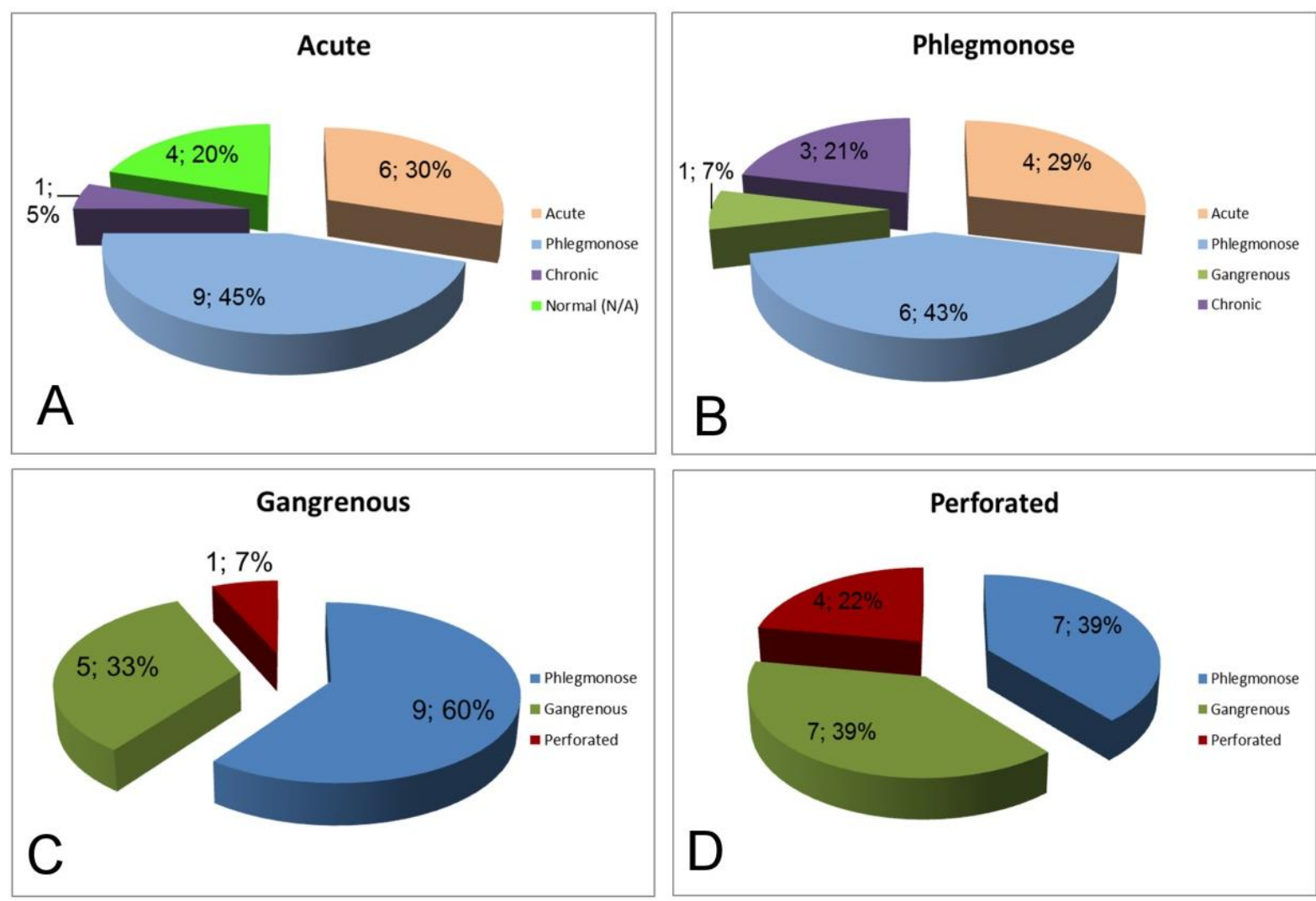

Fig. 2 Histopathology diagnoses in different groups of clinically assessed degree of inflammation and concordance of clinical and histology reports. A - Acute appendicitis, concordance 30\% ; B - Phlegmonous appendicitis, concordance 43\%; C - Gangrenous appendicitis, concordance 33\%; D - Perforated appendicitis, concordance $22 \%$.

\section{Discussion}

Appendicitis is the most common reason for emergency abdominal surgery in children [15] with peak incidence in the second and third decade of life. Average age of patients in our study was 9.77 years. Appendicitis is rare in children younger than 5 and most of them present with perforation. The reasons for low incidence of appendicitis in young children are not clear, but distinct anatomical, pathophysiological and social characteristics of children contribute to high perforation rate in children younger than 5 years. Four of our patients $(5.97 \%)$ were in that age group and half of them had perforations. Slight male preponderance was observed (male: female ratio 1.23), with the highest predominance of boys in group of perforated appendicitis (72\%).

\section{Symptoms and signs}

Abdominal pain was a universally present symptom. Most frequently, it was located in the right lower quadrant. Description of its migratory nature had not been easily obtained, particularly in younger children. Common duration of pain was $12-24 \mathrm{~h}$ before admission. Very short duration of pain, less than 6 hours, was associated with more severe inflammation, while duration of pain more than $48 \mathrm{~h}$ corresponded to either acute or per- forated appendicitis. These findings slightly differ from those of Rothrock and Pagane [16]. Recent suggestions that acute appendicitis in fact may be the result of repeated episodes of inflammation and that acute and perforated appendicitis might be different entities may support our findings $[6,17]$. Vomiting had low sensitivity and specificity in limited number of reports on pediatric patients $[18,19]$. Two-thirds of our patients vomited. Most of the patients with 3-5 episodes of vomitus had ruptured or gangrenous appendicitis. Less than 2 or more than 5 episodes of vomitus corresponded with acute inflammation.

O'Shea et al. [20] reported sensitivity of 0.75 and specificity 0.78 for fever as a symptom of appendicitis, while Andersson et al. [21] found that body temperature provided important diagnostic information, particularly in advanced appendicitis. Normal body temperature from onset of symptoms to admission was present in $52 \%$ of our patients. Nevertheless, $85 \%$ of them had fever after admission. Ten patients (15\%) remained afebrile during hospital course but histopathology showed only one normal appendix (NA).

All children in our series had abdominal tenderness in right lower quadrant (RLQ). Rebound tenderness (Blumberg's sign) was positive in 28 patients $(41.79 \%)$. In adults, rebound tenderness is the single most accurate physical sign, with accuracy of $86 \%$ [18], but its accu- 
racy decreases with age to $43 \%$ in pediatric patients $[18,21]$. Localized guarding in RLQ was present in 8 children (11.94\%) and 6 of them had clinically perforated appendicitis.

\section{Laboratory markers of inflammation}

Mean values of WBC were elevated in patients with acute inflammation and in negative appendectomies but were normal in children with chronic appendicitis ( $p<0.05$; one-way ANOVA; Table 4). Values of $\mathrm{Ne} \%$ were significantly different among histology groups $(\mathrm{p}=$ 0.05; one-way ANOVA; Table 4). Mean values of Ne\% were statistically different between acute and phlegmonous $(p<0.05)$, phlegmonous and chronic $(p<0.01)$ and perforated and chronic ( $\mathrm{p}<0.05)$ appendicitis. Differences in NLR were statistically different between groups with phlegmonous and chronic $(p<0.05)$ and gangrenous and chronic $(\mathrm{p}<0.05)$ inflammation. Differences in values of CRP were not significant $(p>0.05$; one-way ANOVA; Table 4) Three out of 4 patients with chronic appendicitis had normal WBC, Ne\% and NLR, but only one had normal CRP. Among children with negative appendectomy, all inflammatory markers were normal in 2 children and 2 had high levels of WBC and CRP. Results of Siddique et al. [13] as well as our findings, demonstrated that mean values of WBC and CRP increase with severity of inflammation. However, both markers are general markers of inflammation, not specific for appendicitis. Nevertheless, appendicitis cannot be ruled out solely on the basis of normal laboratory findings, in the presence of other suggestive clinical signs.

Accurate assessment of the degree of inflammation has implication on postoperative therapy protocol and complication rate. Overall reported accuracy of macroscopic assessment of the appendix at surgery was $87.3 \%$ [22] with $100 \%$ consensus for perforation, abscess, or gangrene of the appendix. Conversely, Bliss et al. [23] reported greater agreement of surgeon's and pathologist's assessment for normal and acutely inflamed appendices than for more advanced forms. In our study, pediatric surgeons tend to underestimate acute and overestimate more advanced forms of appendicitis (Figure 2). Clinical diagnosis of perforation was established in $26.86 \%$ of patients, with histopathology confirmation in $7.46 \%$ (22\% of concordance). The remaining 14 clinically perforated appendices were histologically either gangrenous or phlegmonous (39\% each). Surgeons tend to classify appendix as perforated in the presence of turbid fluid in abdomen, even if the actual hole in appendix wall has not been visualized. On the other hand, pathologists may omit small holes particularly if the whole appendix has not been examined. Strict definition of perforation as a hole in appendix or free appendicolith in abdomen may improve concordance of surgeon's and pathologist's reports in advanced forms of appendicitis [24]. Diagnosis of chronic appendicitis and negative appendectomy could not be established without histopathology.

Time from admission to operation varied with the severity of inflammation from average of $10 \mathrm{~h} 49 \mathrm{~min}$ for acute to $7 \mathrm{~h} 45 \mathrm{~min}$ for perforated appendicitis. Patients with negative appendectomies were operated on $15 \mathrm{~h} 36 \mathrm{~min}$ and those with chronic inflammation $21 \mathrm{~h} 36$ min after admission. Narsule et al. [6] reported similar results. In patients with milder or equivocal symptoms and signs repeated examinations, laboratory tests and imaging studies may be necessary. On the other hand, children who were septic, dehydrated and with signs of generalized peritonitis on admission, may benefit from short period of IV fluids and antibiotic administration before operation, but this may result in intra-hospital delay of surgery. Yardeni at al. [25] reported that overnight delay of surgery in those patients who presented with non-perforated appendicitis did not significantly affect operating time, rate of perforations or frequency of complications.

Negative appendectomy rate of $6 \%$ in our study is low and comparable with other reports $[6,26]$. Likewise, clinical perforation rate of $26.86 \%$ is similar to other reports [6]. It is biased to some extent with the fact that more than half of children with perforation (10 of 18) was referred from other RGH. The main reason for referral was severe clinical presentation. Six referred patients with perforation of the appendix had clinical signs of acute abdomen and x-ray findings of intestinal obstruction. None of the referred patients were treated in RGH before referral. Perforation was found in 3 patients admitted less than 6 hours after onset of the symptoms. Two of them were operated on within 3 hours after admission. These results may support theories [17] that two distinct populations of patients with appendicitis may exists, and that in some patients, inflammation progresses more rapidly to perforation [6]. Furthermore, this implies that perforation correlates more with prehospital than with in-hospital delay, and that postponing operation for several hours in order to clarify diagnosis in equivocal cases would not increase the risk of perforation [25,27].

In conclusion, clinical presentation of appendicitis in children may vary, from those with very mild symptoms to those with life threatening septic shock and bowel obstruction. Unfortunately, there is neither a single diagnostic test nor a combination of clinical, laboratory, and imaging studies, that have $100 \%$ of sensitivity and/or specificity. Furthermore, there is still no way to distinguish simple acute and perforated appendicitis with certainty before surgery. Delaying surgery for several hours in doubtful cases to clarify diagnosis may further reduce negative appendectomy rates without increasing the risk of perforation. 


\section{References}

1. Sudhakaran N, Ade-Ajayi N. Appendicitis in children. Surgery. Elsevier Ltd; 2010; 28:16-21.

2. Benabbas R, Hanna M, Shah J, Sinert R. Diagnostic Accuracy of History, Physical Examination, Laboratory Tests, and Pointof-care Ultrasound for Pediatric Acute Appendicitis in the Emergency Department: A Systematic Review and Metaanalysis. Alpern E, editor. Acad Emerg Med 2017; 24:523-551.

3. Newman K, Ponsky T, Kittle K, Dyk L, Throop C, Gieseker K, et al. Appendicitis 2000: variability in practice, outcomes, and resource utilization at thirty pediatric hospitals. J Pediatr Surg 2003; 38:372-9-9.

4. Alloo J, Gerstle T, Shilyansky J, Ein SH. Appendicitis in children less than 3 years of age: a 28 -year review. Pediatr Surg Int 2004; 19:777-779.

5. Marjanović Z, Spasić Z, Zivanović D, Kostić A, Djordjević I ZD. Akutni apendicitis kod dece uzrasta do tri godine. Srp Arh Celok Lek 2006; 134:203-207.

6. Narsule CK, Kahle EJ, Kim DS, Anderson AC, Luks FI. Effect of delay in presentation on rate of perforation in children with appendicitis. Am J Emerg Med. Elsevier B.V.; 2010;2-5.

7. Stevenson MD, Dayan PS, Dudley NC, Bajaj L, Macias CG, Bachur RG, et al. Time From Emergency Department Evaluation to Operation and Appendiceal Perforation. Pediatrics. 2017;139.

8. Tsuji M, Puri P, Reen DJ. Characterisation of the local inflammatory response in appendicitis. J Pediatr Gastroenterol Nutr $1993 ; 16: 43-48$

9. Wang Y, Reen D, Puri P. Is a histologically normal appendix following emergency appendicectomy always normal? Lancet. Elsevier. 1996; 347:1076-1079.

10. Nemeth L, Reen DJ, O'Briain DS, McDermott M, Puri P. Evidence of an inflammatory pathologic condition in "normal" appendices following emergency appendectomy. Arch Pathol Lab Med 2001; 125:759-764.

11. Wu Hp, Chen C, Kuo I, Wu Y, Fu Y. Diagnostic Values of a Single Serum Biomarker at Different Time Points Compared with Alvarado Score and Imaging Examinations in Pediatric Appendicitis. J Surg Res. Elsevier Inc; 2012;174:272-177.

12. Andersson REB. Meta-analysis of the clinical and laboratory diagnosis of appendicitis. Br J Surg. 2004;91:28-37.

13. Siddique $\mathrm{K}$, Baruah $\mathrm{P}$, Bhandari S, Mirza S, Harinath $\mathrm{G}$. Diagnostic accuracy of white cell count and C-reactive protein for assessing the severity of paediatric appendicitis. JRSM Short Rep 2011; 2:59.

14. Yazici M, Ozkisacik S, Oztan MO, Gürsoy H. Neutrophil/ lymphocyte ratio in the diagnosis of childhood appendicitis. Turk $\mathbf{J}$ Pediatr 2010; 52:400-403.
15. Morrow SE, Newman KD. Current management of appendicitis. Semin Pediatr Surg 2007; 16:34-40.

16. Rothrock SG, Pagane J. Acute appendicitis in children: emergency department diagnosis and management. Ann Emerg Med 2000; 36:39-51.

17. Livingston EH, Woodward W a, Sarosi G a, Haley RW. Disconnect between incidence of nonperforated and perforated appendicitis: implications for pathophysiology and management. Ann Surg 2007; 245:886-892.

18. Kwok MY, Kim MK, Gorelick MH. Evidence-based approach to the diagnosis of appendicitis in children. Pediatr Emerg Care 2004; 20:690-8-701

19. Golledge J, Scriven M. Peritonism in appendicitis. Ann R Coll Surg Engl 1996; 78:11-14.

20. O'Shea JS, Bishop ME, Alario AJ, Cooper JM, others. Diagnosing appendicitis in children with acute abdominal pain Pediatr Emerg Care 1988; 4:172.

21. Andersson RE, Hugander a P, Ghazi SH, Ravn H, Offenbartl SK, Nyström PO, et al. Diagnostic value of disease history, clinical presentation, and inflammatory parameters of appendicitis. World J Surg 1999; 23:133-140.

22. Roberts JK, Behravesh M, Dmitrewski J. Macroscopic findings at appendicectomy are unreliable: implications for laparoscopy and malignant conditions of the appendix. Int J Surg Pathol 2008; 16:386-390.

23. Bliss D, Mckee J, Cho D, Krishnaswami S, Zallen G, Harrison $\mathrm{M}$, et al. Discordance of the pediatric surgeon's intraoperative assessment of pediatric appendicitis with the pathologists report. J Pediatr Surg. Elsevier Inc.; 2010; 45:1398-1403.

24. St Peter SD, Sharp SW, Holcomb GW, Ostlie DJ. An evidencebased definition for perforated appendicitis derived from a prospective randomized trial. J Pediatr Surg. Elsevier Inc.; 2008; 43:2242-2245.

25. Yardeni D, Hirschl RB, Drongowski RA, Teitelbaum DH, Geiger JD CA. Delayed versus immediate surgery in acute appendicitis: do we need to operate during the night? J Pediatr Surg 2004; 39:464-469.

26. Oyetunji TA, Ong'uti SK, Bolorunduro OB, Cornwell EE 3rd NB. Pediatric negative appendectomy rate: trend, predictors, and differentials. J Surg Res. Elsevier Inc; 2012; 173:16-20.

27. Almström M, Svensson JF, Patkova B, Svenningsson A, Wester T. In-hospital Surgical Delay Does Not Increase the Risk for Perforated Appendicitis in Children. Ann Surg 2017; 265: 616-621. 